Research Article

\title{
ANALYSIS AND SIMULATION OF A THREE-PHASE DELTA INVERTER FOR A STAR- CONNECTED RL LOAD
}

\begin{abstract}
Ahmet G̈̈NDOĞDU ${ }^{1^{*}}$, Reşat ÇELIKEL ${ }^{2}$, Şehmus FIDAN ${ }^{3}$
In this study, analysis and simulation of the electrical and mathematical model of a 3-phase and 3-switch delta inverter that fed a three-phase RL load were performed. First, the Matlab/Simulink model of the inverter was created. In this model, an RL load of $R=10 \Omega$ and $L=0.005 \mathrm{H}$ was fed and various simulations were made. The simulation results were obtained using 3 step switching technique for different conduction modes. The delta inverter that has a simpler structure and less switching elements than conventional inverter structures can be easily realized with low-cost microcontrollers.
\end{abstract}

Key words: Power electronics, DC-AC power converters, Pulse inverters, System analysis and design, Delta inverter.

\section{Introduction}

As in all areas of science and engineering, there have been also significant developments in the field of power electronics in the last 50 years. High efficiency and small volume systems consisting of advanced power electronics circuits have taken the place of low-efficiency, large-volume control systems that can be carried out in classical terms. Instead of direct current motors used in variablespeed control systems having high-dynamic-performance, advanced control methods allowing the use of synchronous, asynchronous and newly developed motor types have been developed [1]. In parallel with the developments in the material field, new and superior motor types have been added to existing motor options and smaller and faster switching elements have been developed. Rapid developments occurring in power electronics switching elements have been effective in the development of power converters and motor drive systems that provide superior control and operation characteristics.

Power inverters are power supplies that ensuring the control of electrical energy. In all control systems where advanced control methods are used, a controllable power supply is needed. In variable

\footnotetext{
${ }^{1}$ Department of Electrical and Electronic Engineering, University of Batman, Batman, Turkey, (agundogdu23@gmail.com) https://orcid.org/0000-0002-8333-3083

2 Department of Electrical and Electronic Engineering, University of Batman, Batman, Turkey, (resat.celikel@gmail.com) https://orcid.org/0000-0002-9169-6466

${ }^{3}$ Department of Electrical and Electronic Engineering, ,University of Batman, Batman, Turkey, (sehmus.fidan@ gmail.com) https://orcid.org/0000-0002-5249-7245
} 
speed applications, the variable voltage and variable frequency required by the motors are provided by power converters known as controlled power supply.

These converter structures used in drive systems are classified in Fig.1[2]. AC-AC converters provide conversion from the alternating current to the alternating current that is at different amplitude and frequency.

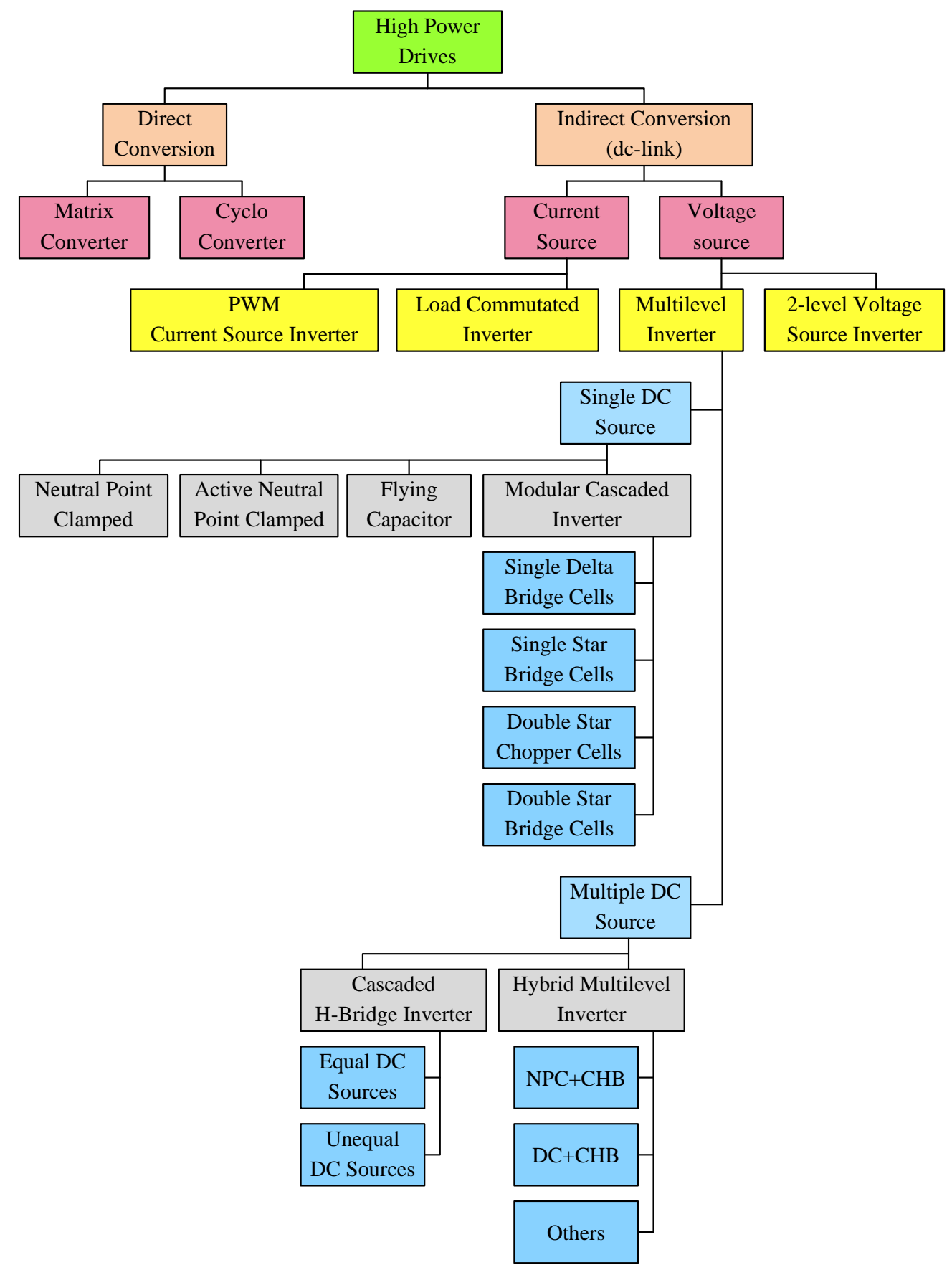

Figure 1. Classification of the power converters.

Depending on the type of power transfer link used between them, this conversion is done in two different ways: i) Single-stage $a c-a c$ conversion (direct link), ii) two-stage $a c-d c$ - $a c$ conversion (dc link) [3]. 
Both types of converters require the use of a large number of semiconductor switching elements and appropriate modulation techniques. In most motor drive systems used in industry, $d c$ link converters that make two-phase conversion are used. These converters are made up of two parts. First, by rectifying the $a c$ input voltage with the help of rectifier circuit, it is converted to the $d c$ voltage. In the second step, with the help of an inverter circuit, this obtained $d c$ voltage is converted to $a c$ voltage at variable amplitude and frequency. According to the configuration of the used $d c$ link, inverters are divided into two sections, voltage source inverters (VSI) and current source inverters (CSI).

The voltage source inverters have large filter capacitors that are at the input terminals and hold the $d c$ link voltage constant. In these inverters, the adjustable output voltage and frequency are independent of the load current. On the other side, the current source inverters provide a more controlled load current with the help of large-value inductors connected in series to the input terminals. That is, the load current is more controlled compared to the voltage. Here, the inverter output voltage depends on the load impedance. Especially the voltage source inverters are widely used in academic studies and industrial applications. Delta inverter, which is from the family of voltage source inverter, was first proposed by Evans and colleagues in 1980 for variable speed drive systems fed from off-grid insulated batteries [12].

Although there are many studies related to the power converters given in Fig. 1 in the literature, the studies related to the delta inverter, which cannot take place in this classification, are limited. In these studies, inverter design and harmonic analysis of it [5,7], vector control application [6], the openloop control of the induction motor [4,16], comparison of the delta inverter with the bridge inverter [8], analysis of the switching techniques having $120^{\circ}$ and $240^{\circ}$ conduction modes [8], speed and torque estimation of the BDCM motor [9], vector control and performance analysis of the BACM motor [10], for large-scale PV systems, a $30 \mathrm{~kW}$ grid-connected delta inverter design and analysis of it [11], self-control application of the BDCM motor with FPGA [13,18], direct torque control of the induction motor with FPGA [14], direct torque control of the induction motor [12,15,22,23], control of the delta inverter with SVPWM [17,19,20], and comparison of RFOC and DTC techniques [21] were performed successfully.

In this study, the electrical and mathematical model of a 3-phase and 3-switch delta inverter that fed a star-connected RL load was analyzed and simulated in Matlab/Simulink environment. The simulation results obtained in different conduction modes were presented comparatively.

\section{Structure of the Delta Inverter}

Inverters are widely used in all areas where variable frequency and voltage are needed [24,25]. Fig. 2 shows the power circuit of the delta inverter, which is a voltage source inverter.

In its structure, there are 3 semiconductor switching elements and 3 insulated equivalent DC sources. A switching element is connected in series with each DC source to form a leg of the inverter. The inverter output voltage is generated with the appropriate modulation of S1, S2 and S3 switches. Each output line voltage is generated by two switching elements. 


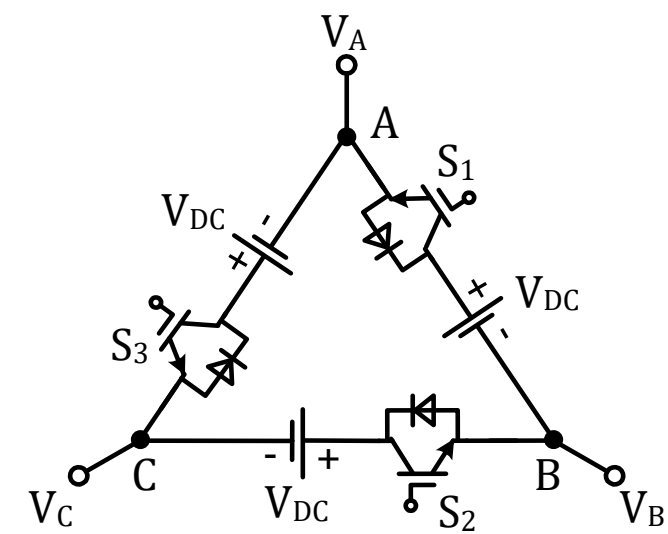

Figure 2. Power circuit of delta inverter.

When the switches on each inverter leg enter the conduction and cutoff respectively, positive and negative alternative voltages emerge at $\mathrm{A}, \mathrm{B}, \mathrm{C}$ points.

In order for the delta inverter to be able to generate a nominal output voltage, only 2 switching elements must be OFF at any instant of " $t$ " time. If one switching element is OFF and the other two are in the ON position, the inverter cannot generate the voltage and current required for the load. If all three switching elements are in OFF position in the same " $t$ " instant, then the inverter is short circuited. Short-circuit currents at high-value occur and damage the inverter. To avoid short circuit, 3 switching elements must not be in the conduction at the same time.

For the switching elements, the state of being in the conduction is expressed with 1 and the state of being in cutoff is expressed with 0 . Accordingly, $S_{A}, S_{B}, S_{C}$ switching functions can be written as follows,

$S_{A, B, C}=\left\{\begin{array}{ccc}1, & S_{1}, S_{2}, S_{3} & O N \\ 0, & S_{1}, S_{2}, S_{3} & \text { OFF }\end{array}\right.$

According to this definition, $2^{3}=8$ different switching states forming the $V_{A}, V_{B}, V_{C}$ voltages at inverter output is obtained. For each switching state, delta inverter generates 8 different voltage vectors. Six of these voltage vectors $\left(V_{l}, V_{2}, V_{3}, V_{4}, V_{5}\right.$, and $\left.V_{6}\right)$ are called as "active" voltage vector. Among these, $V_{l}, V_{3}, V_{5}$ vectors are called "low-amplitude", $V_{2}, V_{4}, V_{6}$ vectors are called "highamplitude" voltage vectors. Fig. 3 shows the switching states corresponding to each of the 6 active voltage vectors generated clockwise at inverter output according to the being in conduction and cutoff states, respectively.

The $V_{0}$ vector is obtained in the case of $S_{1}=S_{2}=S_{3}=0$ where all switching elements are in cutoff and is called "zero" voltage vector. When the zero voltage vector is applied, the source currents and the external circuit currents become zero. 


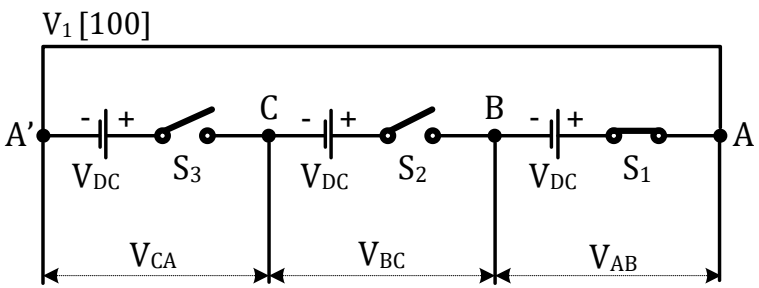

a)

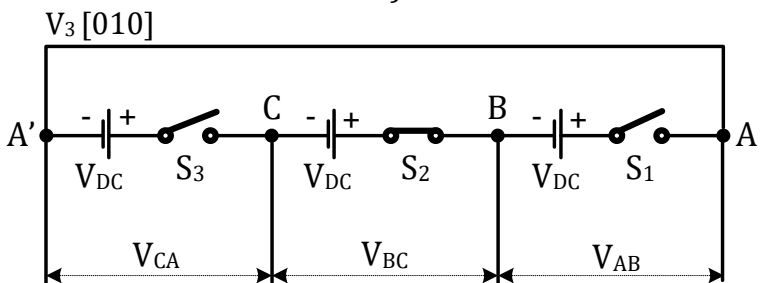

c)

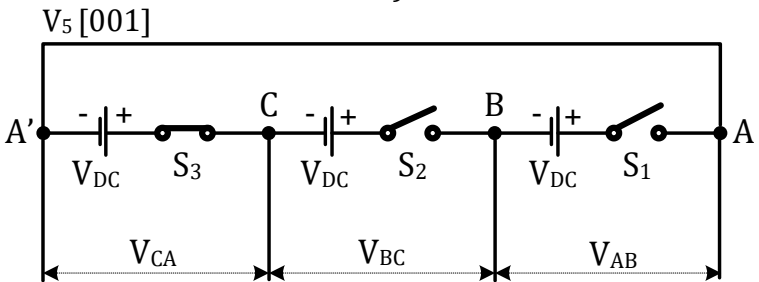

e)

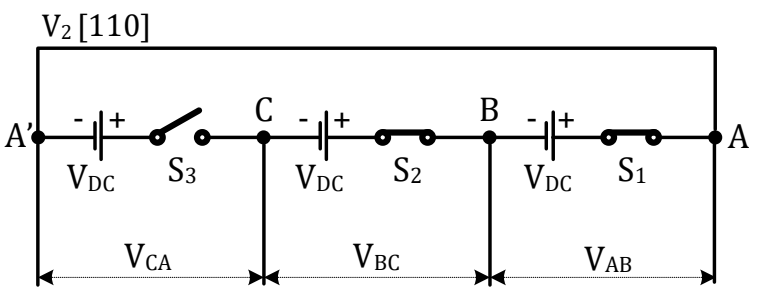

b)

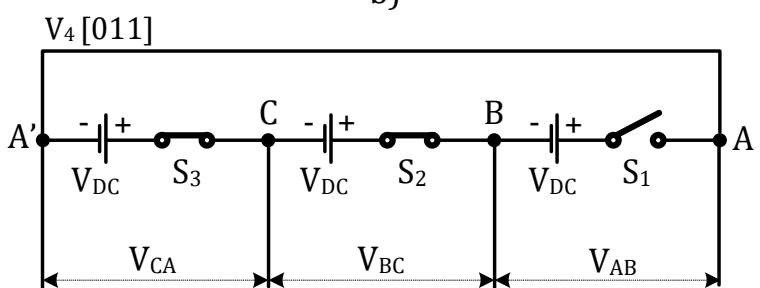

d)

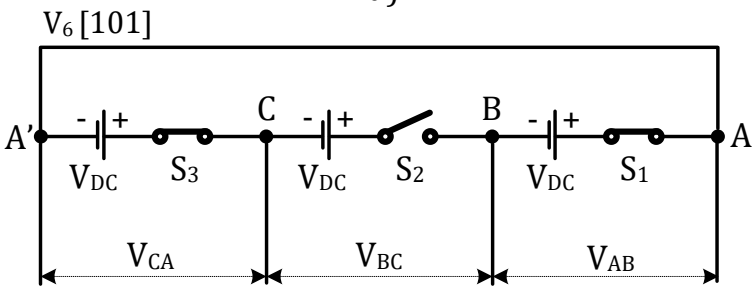

f)

Figure 3. Switching states.

The $V_{7}$ vector is obtained in the case of $S_{1}=S_{2}=S_{3}=1$ where all switching elements are in the conduction and is called the "short circuit" voltage vector. The $V_{7}$ vector causes high-value short circuit currents to flow by making the inverter short circuit. Therefore, $V_{7}$ voltage vector should not be applied in practice. The inverters output voltages, which are obtained depending on the switching states given in Fig. 3, are shown in Table I.

Table 1. Switching conditions and line to line voltages

\begin{tabular}{|c|c|c|c|c|c|c|}
\hline $\mathbf{S}_{\mathbf{1}}\left(\mathbf{S}_{\mathbf{A}}\right)$ & $\mathbf{S}_{\mathbf{2}}\left(\mathbf{S}_{\mathbf{B}}\right)$ & $\mathbf{S}_{\mathbf{3}}\left(\mathbf{S}_{\mathbf{C}}\right)$ & $\mathrm{V}_{0,7}$ & $\mathrm{~V}_{\mathrm{AB}}$ & $\mathrm{V}_{\mathrm{BC}}$ & $\mathrm{V}_{\mathrm{CA}}$ \\
\hline $\mathbf{0}$ & $\mathbf{0}$ & $\mathbf{0}$ & $\mathrm{V}_{0}[000]$ & 0 & 0 & 0 \\
\hline $\mathbf{1}$ & $\mathbf{0}$ & $\mathbf{0}$ & $\mathrm{V}_{1}[100]$ & $\mathrm{V}_{\mathrm{DC}}$ & 0 & 0 \\
\hline $\mathbf{1}$ & $\mathbf{1}$ & $\mathbf{0}$ & $\mathrm{V}_{2}[110]$ & $\mathrm{V}_{\mathrm{DC}}$ & $\mathrm{V}_{\mathrm{DC}}$ & $-2 \mathrm{~V}_{\mathrm{DC}}$ \\
\hline $\mathbf{0}$ & $\mathbf{1}$ & $\mathbf{0}$ & $\mathrm{V}_{3}[010]$ & 0 & $\mathrm{~V}_{\mathrm{DC}}$ & 0 \\
\hline $\mathbf{0}$ & $\mathbf{1}$ & $\mathbf{1}$ & $\mathrm{V}_{4}[011]$ & $-2 \mathrm{~V}_{\mathrm{DC}}$ & $\mathrm{V}_{\mathrm{DC}}$ & $\mathrm{V}_{\mathrm{DC}}$ \\
\hline $\mathbf{0}$ & $\mathbf{0}$ & $\mathbf{1}$ & $\mathrm{V}_{5}[001]$ & 0 & 0 & $\mathrm{~V}_{\mathrm{DC}}$ \\
\hline $\mathbf{1}$ & $\mathbf{0}$ & $\mathbf{1}$ & $\mathrm{V}_{6}[101]$ & $\mathrm{V}_{\mathrm{DC}}$ & $-2 \mathrm{~V}_{\mathrm{DC}}$ & $\mathrm{V}_{\mathrm{DC}}$ \\
\hline $\mathbf{1}$ & $\mathbf{1}$ & $\mathbf{1}$ & $\mathrm{V}_{7}[111]$ & 0 & 0 & 0 \\
\hline
\end{tabular}

From these vectors, $V_{l}, V_{3}, V_{5}$ vectors connect only one DC source in the inverter to the twophase end of the three-phase load. In this case, a voltage as much as $V_{D C} / 2$ is applied to both phase windings of the load. Therefore, these vectors are low amplitude vectors in terms of their effect on the windings. At any instant of " $t$ " time, the $V_{2}, V_{4}, V_{6}$ vectors connect two DC sources in the inverter between each three-phase winding ends of the three-phase load. In also this case, a voltage as much as 
$V_{D C}$ is applied to both phase windings of the load. These vectors are high-amplitude vectors in terms of the effect they created on the winding. $V_{0-7}$ vectors are defined by the Equation 2.

$V_{0,7}\left(S_{A} S_{B} S_{C}\right)=\left\{\begin{array}{lr}\mathrm{V}_{1}=\mathrm{V}_{3}=\mathrm{V}_{5}, \text { Low amp. vector } \\ \mathrm{V}_{2}=\mathrm{V}_{4}=\mathrm{V}_{6}, \text { High amp. vector } \\ \mathrm{V}_{0,} \quad \text { Zero volt. vector } \\ \mathrm{V}_{7,} & \text { Short Circuit volt. vector }\end{array}\right.$

\section{Delta Inverters and Star-Connected Load}

In Fig. 4, the connection of a 3-phase star-connected RL load to the delta inverter is presented.

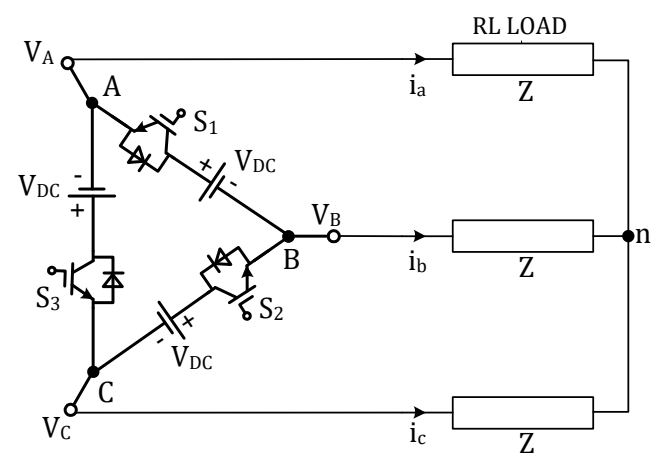

Figure 4. The RL load that is star-connected to the delta inverter.

According to this connection, $V_{A n}, V_{B n}, V_{C n}$ phase-neutral voltages can be written as a result of the $S_{A}$, $S_{B}, S_{C}$ switching functions, as in Equations 3-4-5.

$$
\begin{aligned}
& V_{A n}=\frac{V_{D C}}{2}\left(S_{A}-S_{C}\right)\left(S_{B}+1\right) \\
& V_{B n}=\frac{V_{D C}}{2}\left(S_{B}-S_{A}\right)\left(S_{C}+1\right) \\
& V_{C n}=\frac{V_{D C}}{2}\left(S_{C}-S_{B}\right)\left(S_{A}+1\right)
\end{aligned}
$$

The $\alpha \beta$ components in the stationary axis frame of phase-neutral voltages are calculated by Equation 6-7.

$$
\begin{aligned}
& V_{\alpha}=V_{A n} \cdot \operatorname{Cos}(\theta)+V_{B n} \cdot \operatorname{Cos}\left(\theta+120^{\circ}\right)+V_{C n} \cdot \operatorname{Cos}\left(\theta+240^{\circ}\right) \\
& V_{\beta}=V_{A n} \cdot \operatorname{Sin}(\theta)+V_{B n} \cdot \operatorname{Sin}\left(\theta+120^{\circ}\right)+V_{C n} \cdot \operatorname{Sin}\left(\theta+240^{\circ}\right)
\end{aligned}
$$

Here, the conversion coefficient matrix obtained by taking $\theta=0^{0}$ is given in Equation 8. This coefficient matrix will be used in later motor control applications.

$$
\left[\begin{array}{l}
V_{\alpha} \\
V_{\beta}
\end{array}\right]=\sqrt{\frac{2}{3}}\left[\begin{array}{ccc}
1 & -1 / 2 & -1 / 2 \\
0 & \sqrt{3} / 2 & -\sqrt{3} / 2
\end{array}\right]\left[\begin{array}{l}
V_{A n} \\
V_{B n} \\
V_{C n}
\end{array}\right]
$$


$V_{A n}, V_{B n}, V_{C n}$ phase-neutral voltages and $V_{\alpha}, V_{\beta}$ components of the $V_{l-6}$ vectors that form these voltages are given in Table II.

Table II. Switching conditions, phase-neutral voltages and Valpha, Vbeta voltages

\begin{tabular}{|c|c|c|c|c|c|c|c|c|c|}
\hline $\mathbf{S}_{\mathbf{1}}\left(\mathbf{S}_{\mathbf{A}}\right)$ & $\mathbf{S}_{\mathbf{2}}\left(\mathbf{S}_{\mathbf{B}}\right)$ & $\mathbf{S}_{\mathbf{3}}\left(\mathbf{S}_{\mathbf{C}}\right)$ & $\mathrm{V}_{0,7}$ & $\mathrm{~V}_{\mathrm{An}}$ & $\mathrm{V}_{\mathrm{Bn}}$ & $\mathrm{V}_{\mathrm{Cn}}$ & $\mathrm{V}_{\alpha}$ & $\mathrm{V}_{\beta}$ & $V_{J=0,7}$ \\
\hline $\mathbf{0}$ & $\mathbf{0}$ & $\mathbf{0}$ & $\mathrm{V}_{0}[000]$ & 0 & 0 & 0 & 0 & 0 & 0 \\
\hline $\mathbf{1}$ & $\mathbf{0}$ & $\mathbf{0}$ & $\mathrm{V}_{1}[100]$ & $\frac{V D C}{2}$ & $-\frac{V D C}{2}$ & 0 & $\frac{3 V D C}{2 \sqrt{6}}$ & $-\frac{V D C}{2 \sqrt{2}}$ & $\frac{1}{\sqrt{2}} V D C$ \\
\hline $\mathbf{1}$ & $\mathbf{1}$ & $\mathbf{0}$ & $\mathrm{V}_{2}[110]$ & $V D C$ & 0 & $-V D C$ & $\frac{3 V D C}{\sqrt{6}}$ & $\frac{V D C}{\sqrt{2}}$ & $\sqrt{2} V D C$ \\
\hline $\mathbf{0}$ & $\mathbf{1}$ & $\mathbf{0}$ & $\mathrm{V}_{3}[010]$ & 0 & $\frac{V D C}{2}$ & $-\frac{V D C}{2}$ & 0 & $\frac{V D C}{\sqrt{2}}$ & $\frac{1}{\sqrt{2}} V D C$ \\
\hline $\mathbf{0}$ & $\mathbf{1}$ & $\mathbf{1}$ & $\mathrm{V}_{4}[011]$ & $-V D C$ & $V D C$ & 0 & $-\frac{3 V D C}{\sqrt{6}}$ & $\frac{V D C}{\sqrt{2}}$ & $\sqrt{2} V D C$ \\
\hline $\mathbf{0}$ & $\mathbf{0}$ & $\mathbf{1}$ & $\mathrm{V}_{5}[001]$ & $-\frac{V D C}{2}$ & 0 & $\frac{V D C}{2}$ & $-\frac{3 V D C}{2 \sqrt{6}}$ & $-\frac{V D C}{2 \sqrt{2}}$ & $\frac{1}{\sqrt{2}} V D C$ \\
\hline $\mathbf{1}$ & $\mathbf{0}$ & $\mathbf{1}$ & $\mathrm{V}_{6}[101]$ & 0 & $-V D C$ & $V D C$ & 0 & $-\frac{2 V D C}{\sqrt{2}}$ & $\sqrt{2} V D C$ \\
\hline $\mathbf{1}$ & $\mathbf{1}$ & $\mathbf{1}$ & $\mathrm{V}_{7}[111]$ & 0 & 0 & 0 & 0 & 0 & 0 \\
\hline
\end{tabular}

The regions of the $V_{\alpha}$ and $V_{\beta}$ components forming the $V_{l-6}$ vectors and their polarities are given in Table III.

Table III. Polarities and regions of Valpha, Vbeta components and conduction modes the active voltage vectors.

\begin{tabular}{|c|c|c|c|c|c|c|}
\hline & & & & \multicolumn{3}{|c|}{ Conduction Modes } \\
\hline & $\alpha$ & $\beta$ & region & $120^{\circ}$ & $180^{\circ}$ & $240^{\circ}$ \\
\hline $\mathrm{V}_{1}$ & + & - & 4 & ○ & ○ & - \\
\hline $\mathrm{V}_{2}$ & + & + & 1 & - & ○ & ○ \\
\hline$V_{3}$ & 0 & + & $+\beta$ & ○ & ○ & - \\
\hline $\mathrm{V}_{4}$ & - & + & 2 & - & ○ & ○ \\
\hline$V_{5}$ & - & - & 3 & ○ & ○ & - \\
\hline $\mathrm{V}_{6}$ & 0 & - & $-\beta$ & - & ○ & 0 \\
\hline
\end{tabular}

The schematic representation of $V_{l-6}$ vectors, whose polarities and regions are given in Table III, on the $\alpha \beta$ plane is given in Fig. 5. $V_{l-6}$ voltage vectors formed by $V_{\alpha}, V_{\beta}$ voltages in $\alpha \beta$ plane are given in Equation 9 in terms of amplitude. As seen, in terms of amplitude, $V_{2}, V_{4}, V_{6}$ vectors have two times more amplitude compared with the $V_{1}, V_{3}, V_{5}$ vectors.

$\frac{\left|V_{2}\right|=\left|V_{4}\right|=\left|V_{6}\right|=\sqrt{2} V_{D C}}{\left|V_{1}\right|=\left|V_{3}\right|=\left|V_{5}\right|=\frac{1}{\sqrt{2}} V_{D C}}=2$ 


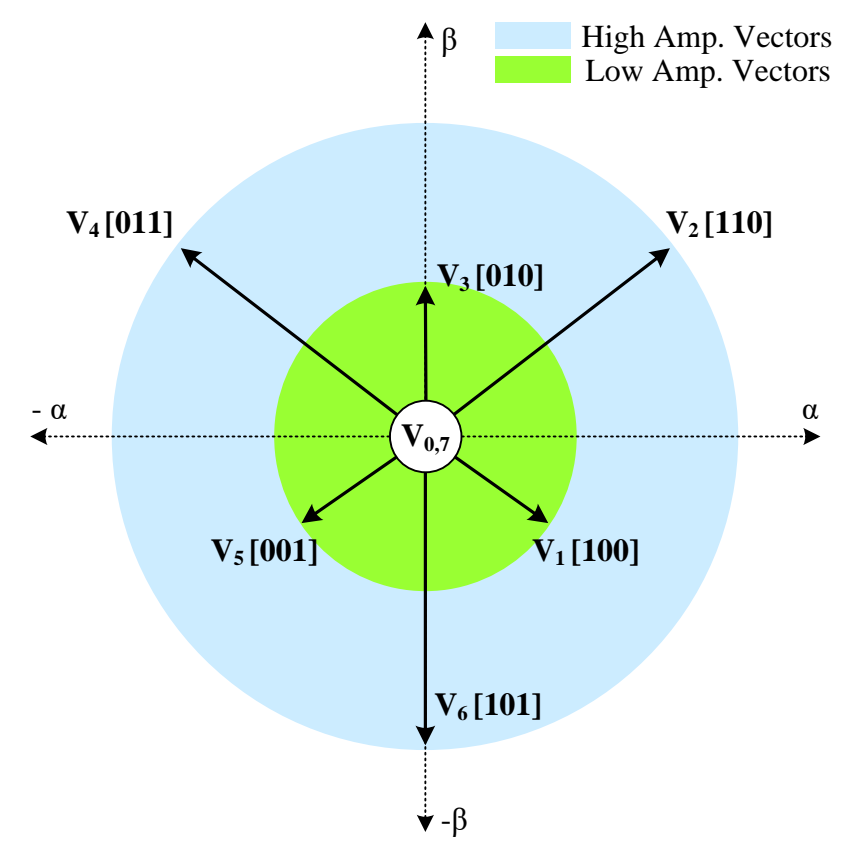

Figure 5. Schematic representation of $V_{1-6}$ vectors.

\section{Modulation Technique}

Electrical drives are widely used in control and automation systems. These drives can be examined in two different parts, the power and control sections. In the power section, switching power supplies, called controlled power supply, converters and inverters are used. On the other hand, the control section includes modulation techniques (MT) which change both the waveform and amplitude of the output voltage of these controlled power supplies at the desired intervals.

Many different modulation techniques have been developed for the control of electrical drive systems whose detailed classification is given in Fig. 1. The most commonly known of these techniques are: Six-step switching, Pulse Width Modulation, Sinusoidal PWM, space vector PWM, and Hysteresis Band switching technique.

At the end of the analysis conducted in this study, it has been observed that for a 3-phase delta inverter, depending on the switching combination of 3 IGBT, there are three different conduction modes. These are $120^{\circ}$ conduction mode, $180^{\circ}$ conduction mode, and $240^{\circ}$ conduction mode. Each conduction mode requires a different modulation process. In a one-period duration, $120^{\circ}$ conduction mode and $240^{\circ}$ conduction mode take place within 3 steps. On the other hand, $180^{\circ}$ conduction mode takes place within 6 steps. The voltage vectors that are active in each conduction mode are given in Table III.

As can be seen from the Table III, whereas $V_{1}, V_{3}, V_{5}$ voltage vectors with low amplitude are used in $120^{\circ}$ conduction mode, $V_{2}, V_{4}, V_{6}$ vectors with high amplitude are used in $240^{\circ}$ conduction mode. In $180^{\circ}$ conduction mode, all of the $V_{I^{-}} V_{6}$ vectors are switched together. Depending on these active voltage vectors, the inverter shows different behavior in each conduction mode. In this way, different voltages with low and high amplitude can be obtained at the inverter output. In this regard, 
delta inverter can be used in many different applications. Using these three basic conduction modes, more advanced different modulation algorithms can also be developed.

For the $120^{\circ}, 180^{\circ}$ and $240^{\circ}$ conduction modes, switching states, phase-neutral voltages that can be obtained from the inverter output, and phase-phase voltages are shown in Fig. 6. These graphs are obtained in the condition in which the load connected to the inverter output is star-connected.
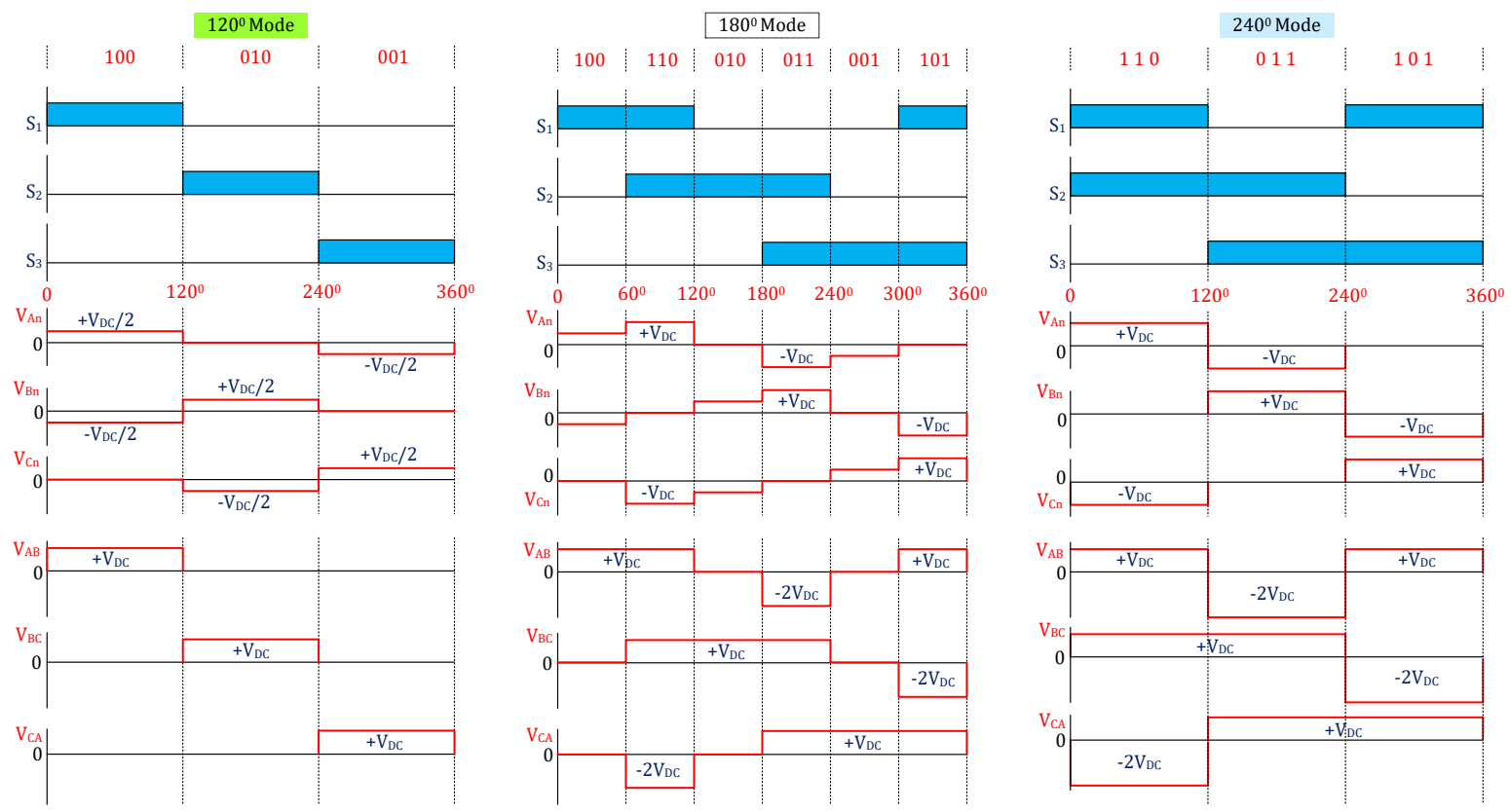

Figure 6 . For $120^{\circ}, 180^{\circ}$ and $240^{\circ}$ conduction modes, switching states, phase-neutral voltages that can be obtained from inverter output, and phase-phase voltages

\section{Simulation Model}

Fig. 7 shows the Matlab/Simulink block diagram created for the analysis of a star-connected 3-phase RL load fed by the delta inverter. The current graphs obtained for the conduction modes examined in detail in section IV are given below.

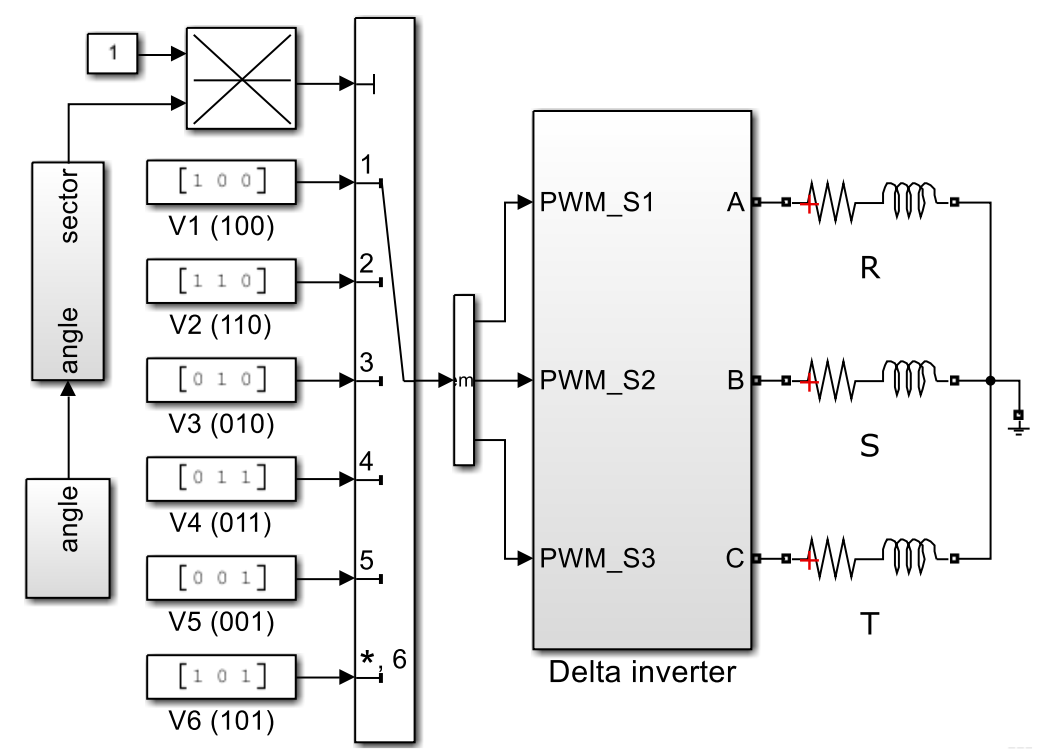

Figure 7. Matlab/Simulink block diagram for star-connected 3-phase RL load. 
For modulation, switching elements were switched by selecting $120^{\circ}, 180^{\circ}$ and $240^{\circ}$ conduction modes. Fig. 8 shows the angular change graph of the modulation signal, from which these conduction modes are obtained, and the sectors. This modulation signal, which was obtained by the movement of the unit vector with $50 \mathrm{~Hz}$ scanning frequency in the $360^{\circ}$ circular plane, was divided into 3 regions of 120-degree within a one-period of time. These regions are called sectors and different switches are switched sequentially in each sector.
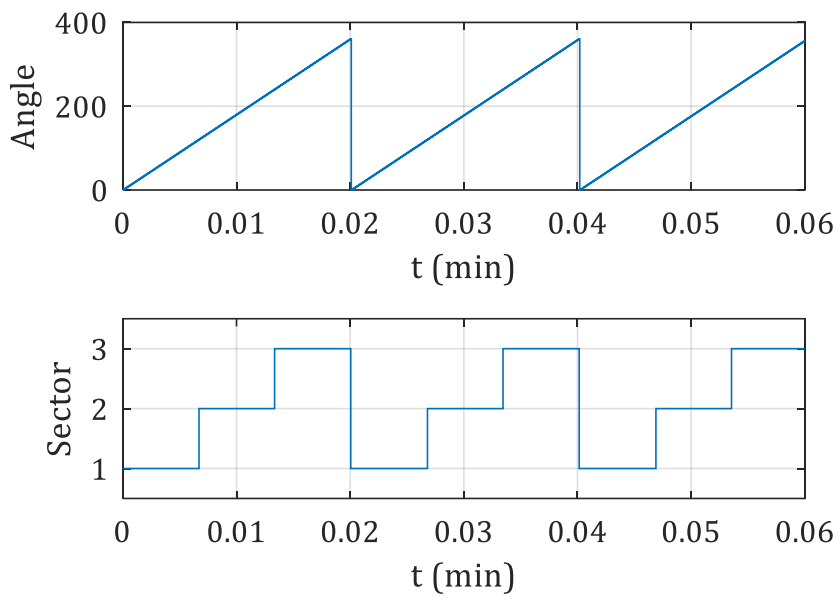

Figure 8. Angular change graph of modulation signal and sectors.

The change of this given modulation signal was carried out and simulations were performed primarily in $120^{\circ}$ conduction mode by using sectors, and the graph for the obtained load current is given in Fig. 9. In this conduction mode, at any instant of " $t$ " time, only a DC source and a switching element are on. Because the DC source voltage disperses equally on both phase windings, the phase currents have I/2 amplitude. Any two of the star-connected 3 phase windings are equal to each other in terms of amplitude, but they are in opposite directions. Since the third winding is not active, this winding current is zero.
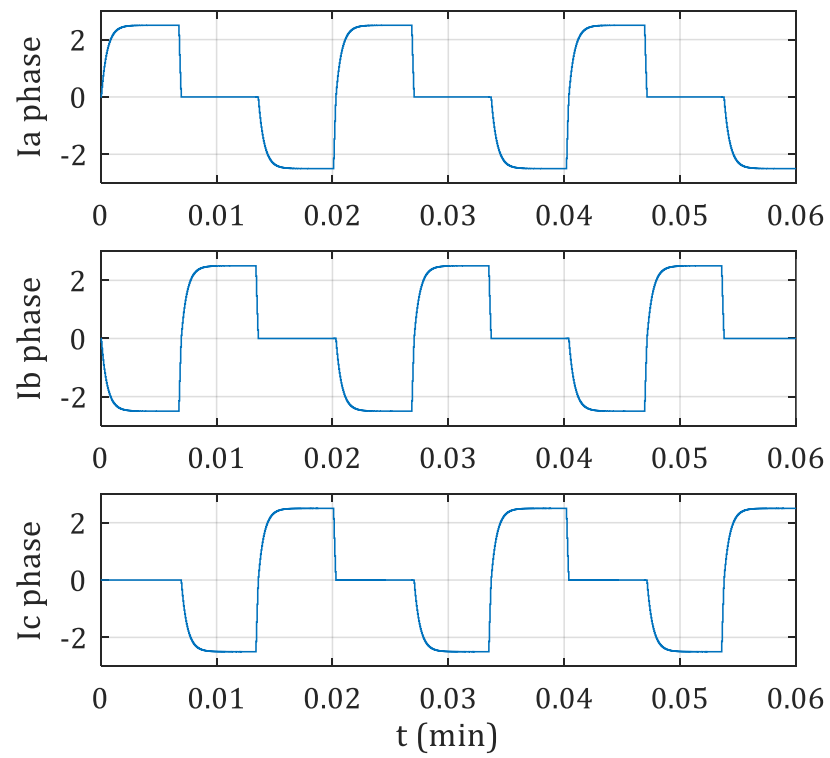

Figure 9.3 phase load currents obtained in $120^{\circ}$ conduction mode.

The graph of the load current obtained in $240^{\circ}$ conduction mode is given in Fig. 10. In this 
conduction mode, two switching elements and two DC sources are active at any instant of " $t$ " time. Because both sources are connected in series, the total end voltage is as much as $-2 V_{D C}$ and each winding voltage is as much as $V_{D C}$. Winding currents have " $P$ " amplitude. Any two of the 3 phase starconnected windings are equal to each other in terms of amplitude, but they are in opposite directions. Since the first and second winding currents flow in reverse direction over the third winding, this winding current is zero. Fig. 11 shows the graphs belonging to the phase and line voltages obtained in $240^{\circ}$ conduction mode. In terms of amplitude, the winding phase voltages are as much as $+V_{D C}$ and $V_{D C}$ and line voltages are as much as $V_{A B}=V_{D C}, V_{B C}=V_{D C}, V_{C A}=-2 V_{D C}$, respectively.
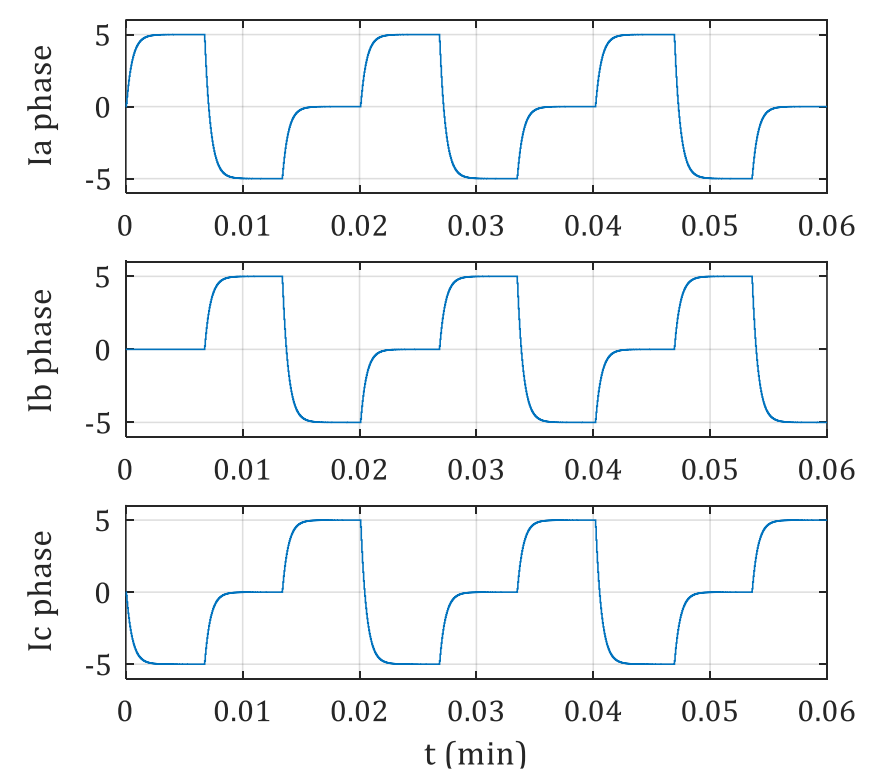

Figure 10. 3-phase load currents obtained in $240^{\circ}$ conduction mode.
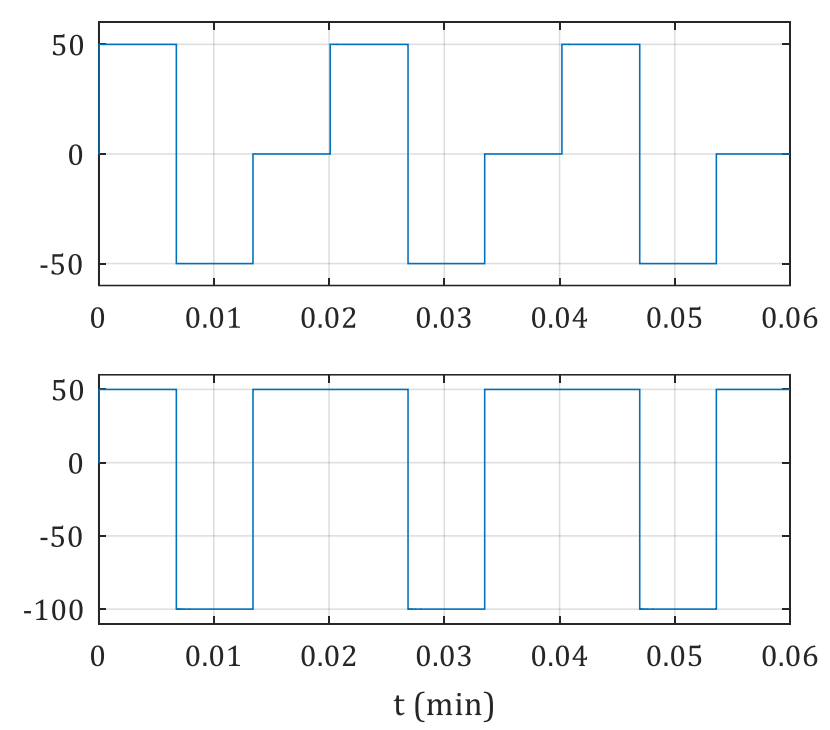

Figure 11. Phase and line voltages obtained in $240^{\circ}$ conduction mode.

The graphs of the load current obtained in $180^{\circ}$ conduction mode are given in Fig. 12. This conduction mode is obtained by the use of $120^{\circ}$ and $240^{\circ}$ conduction modes together. Each phase current is formed by the synthesis of the phase currents with $I / 2$ and I amplitude. 

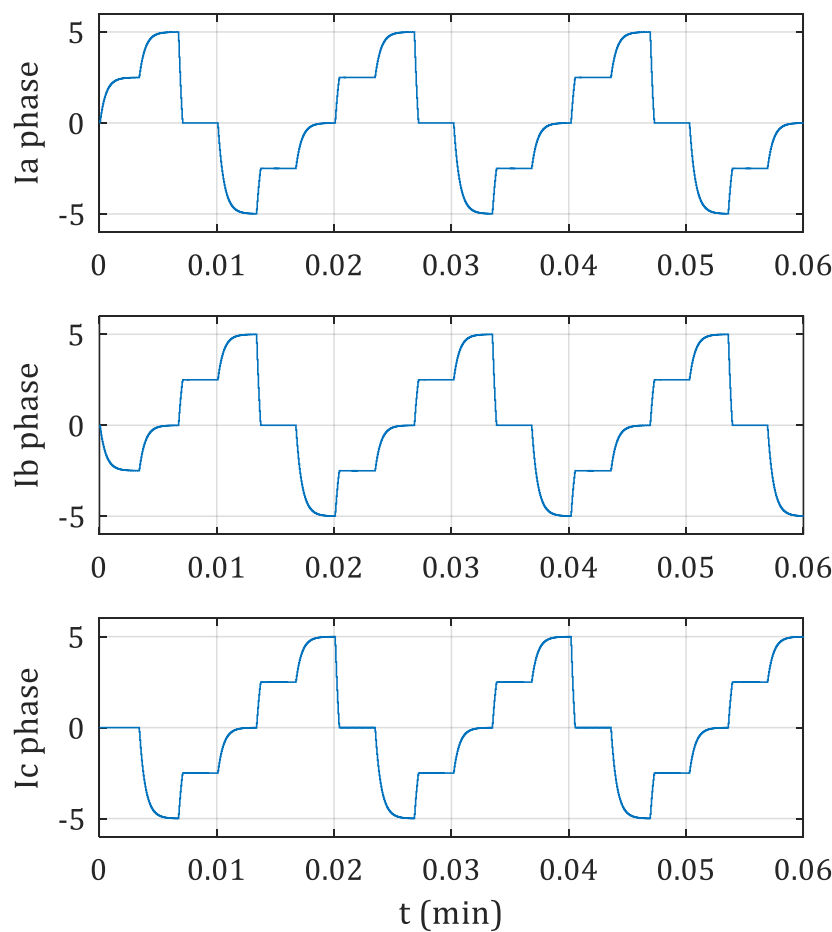

Figure 12. 3-phase load currents obtained in $180^{\circ}$ conduction mode.

Moreover, in Fig. 13, the $\mathrm{I}_{\text {ha }}$ currents obtained from a_phase in each three conduction modes are given in a single graph.
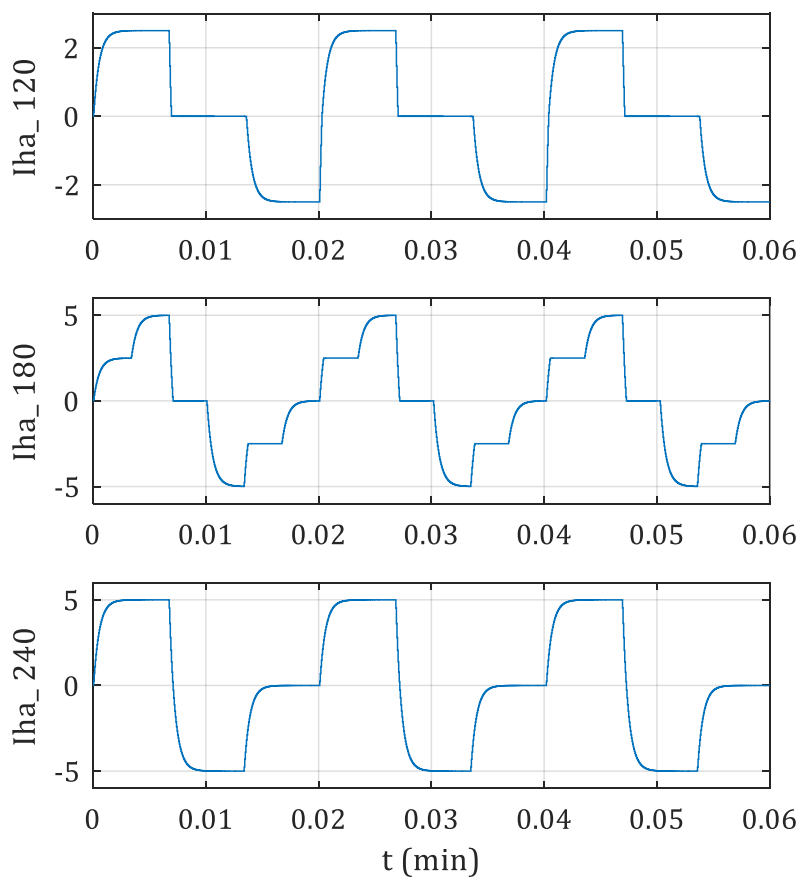

Figure 13. A phase currents obtained in $120^{\circ}, 180^{\circ}, 240^{\circ}$ conduction modes.

\section{Conclusion}

In this study, analysis of the electrical and mathematical model of a three-phase three-switch delta inverter feeding a three-phase RL load was performed. By feeding an RL load having $R=10 \Omega$ 
and $\mathrm{L}=0.005 \mathrm{H}$ through the simulation model, various results were obtained. The simulation results were obtained using three-step switching techniques for different conduction modes of $120^{\circ}, 180^{\circ}$, and $240^{\circ}$. In all three conduction modes, one of the phase winding currents is zero. This is a problem for three-phase star-connected loads fed by balanced sinusoidal voltages. In this respect, delta inverter should be analyzed separately for the loads with different connection group. The delta inverter having a simpler structure and less switching elements than conventional inverter structures can be easily realized with low-cost microcontrollers. Conduction and switching losses are low. For three phase and six phase brushless DC motors and stepper motors fed with more sequential voltages, it has an appropriate driver characteristic.

\section{References}

[1] Miller, E. J., 1989. Brushless Permanent Magnet and Reluctance motor Drivers, Oxford University Pres, Oxford.

[2] Natarajan, P., Kaliannan, P., 2017. A comprehensive review on reduced switch multilevel inverter topologies, modulation techniques and applications, Renew. and Sust. Energy Rev.,76, 12481282.

[3] Ozpineci, B., Tolbert, L.M., 1999. Cycloconverters, IEEE, Power Electronics Society Tutorials Webpage.

[4] Evans, P.D., Dodson, R.C., Eastham, J.F., et al., 1980. Delta inverter, Proceedings. IEE, vol. 127, No:6, 333-340.

[5] Trzynadlowski, A.M., Ji, S., Legowski, S., 1991. Random pulse width modulation of delta inverter for automotive applications, Conference Record of the IEEE Industry Applications Society Annual Meeting, 826-833.

[6] Trzynadlowski, A.M., Legowski, S., 1992. Vector control of delta inverter, Conference Record of the IEEE Industry Applications Society Annual Meeting, vol.1, 1050-1057.

[7] Evans, P.D., Dodson, R.C., Eastham, J.F., 1984. Sinusoidal Pulsewidth Modulation Strategy for the Delta Inverter, IEEE Transactions on Industry Applications, vol. IA-20, no.3, 651-655.

[8] Brooks, D.M., Fisher, G.A., Oates, C., et al. 1982. Discussion on 'delta inverter, IEE Proc. B Electric Power Applications, 129(2), 177-179.

[9] Rhouma, A.B., Masmoudi, A., 2010. Torque and Speed Estimators to be Implemented in a Control Strategy Dedicated to TSTPI-Fed BDCM Drives, $20107^{\text {th }}$ International Multi-Conference on Systems, Signals and Devices.

[10] Affene, A., Masmoudi, A., Rhouma, A.B., 2013. Investigation of the Performance of a VectorControlled Delta-Inverter Fed BACM Drive, Eighth International Conference and Exhibition on Ecological Vehicles and Renewable Energies (EVER), 1-4. 
[11] Sandoval, J.J., Ramos.Ruiz, J., Daniel, M., et al. 2014. A new delta inverter system for grid integration of large scale photovoltaic power plants, IEEE Applied Power Electronics Conf. Exposition - APEC 2014, 1255-1262.

[12] Ouarda, A., Nouira, I., Badsi, B.E., Masmoudi, A., 2014. DTC Strategies Dedicated to IM Drives Fed by Reduced- Structure Inverters Emulating the Conventional One: Application to Low-Cost Automotive Actuators, 2014 17th International Conference on Electrical Machines and Systems (ICEMS), 169-174.

[13] Alouane, A., Rhouma, A.B., Khedher, A., 2014. FPGA Implementation of a dedicated selfcontrol strategy for a delta inverter fed BDCM Drive, International conference on science and electric technology in Magreb (CISTEM), Tunis, 1-8.

[14] Alouane, A., Rhouma, A.B., Kheder, A., 2014. FPGA implementation of a dtc strategy dedicated to three-switch three-phase inverter-fed induction motor drives, 15th Int. Conf. Sciences and Techniques of Automatic Control and Computer Eng., 202-208.

[15] Nouira, I., Badsi, B.E., Masmoudi, A., 2015. DTC of three-switch three-phase inverter fed induction motor drives, Tenth Intern. Conf. on Ecological Vehicles and Renewable Energies (EVER), 1-8.

[16] Badsi, I.N.E., Badsi, B.E., Masmoudi, A., 2016. Space vector PWM techniques for B3-VSI fed three-phase IM drives, IEEE Vehicle Power and Propulsion Conf., 1-6.

[17] Mahdhi, H., Rhouma, A.B., Hamouda, M., 2016. A New Space Vector Modulation Strategy for Three- Switch Three-Phase Delta Inverter, 7th Int. Conf. on Sciences of Electronics, Technologies of Information and Telecommunications, 455-460.

[18] Alouane, A., Rhouma, A.B., Khedher, A., 2016. A self-control strategy for a delta inverter fed BDCM Drive using Xilinx system generator with fixed point/floating point mode, 17th int. conf. on Sciences and Techniques of Automatic control \& computer engineering-STA'2016, 468-474.

[19] Alouane, A., Rhouma, A.B., Hamouda, M., Khedher, A., 2018. Efficient FPGA-based real-time Implementation of an SVPWM Algorithm for a Delta Inverter, IET Power Electronics, Vol: 11, No: 9, 1611-1619.

[20] Badsi, I.N.E., Badsi, B.E., Masmoudi, A., 2018. Carrier-Based and Space Vector PWM Techniques for Delta Inverter Fed IM Drive Operating in Linear and Overmodulation Ranges, 15th Int. Multi-Conf. on Systems, Signals \& Devices, 1323-1328.

[21] Badsi, I.N.E., Badsi, B.E., Masmoudi, A., 2018. RFOC and DTC Strategies for Reduced Structure B3-Inverter Fed Induction Motor Drives, 15th International Multi-Conference on Systems, Signals \& Devices, 1317-1322.

[22] Badsi, B.E., 2013. Six-Switch Inverter Emulation Based DTC Strategy Dedicated to ThreeSwitch Inverter-Fed Induction Motor Drives, Computation and Mathematics in Electrical and Electronic Engineering, vol. 32, no. 1, 289-301.

[23] Badsi, I.N.E., Badsi, B.E., Masmoudi, A., 2018. DTC strategies for three-switch three-phase inverter-fed induction motor drives, COMPEL-The international journal for computation and mathematics in electrical and electronic engineering 37:6, 2176-2194. 
[24] İnci, M., 2019. Performance Analysis of T-type Inverter Based on Improved Hysteresis Current Controller, Balkan Journal of Electrical \& Computer Engineering, vol. 7, no. 2, 149-155.

[25] Asker, M.E., K1lic, H., 2017. Modulation Index And Switching Frequency Effect On Symmetric Regular Sampled SPWM, European Journal of Technic, vol. 7, no. 2, 102-109. 